\title{
A UNIVERSITY REINVENTS ITSELF: A CASE STUDY FOR UNDERSTANDING STRATEGIC MERGERS AND INTEGRATION BETWEEN ACADEMIC INSTITUTIONS
}

\author{
Hana BOR ${ }^{1}$ \\ Avraham KETKO ${ }^{2}$
}

\begin{abstract}
The present research takes a case study approach to understanding the academic merger process by analyzing the 2009 merger between Baltimore Hebrew University (BHU) and Towson University (TU). Based upon the interviews with fifteen stakeholders involved in the BHU / TU merger, we detail the sequence of events from their point of view, and consider how this sequence applies to the stages of the methodological process of mergers within an academic context. Factors that eventually led to successful implementation of the BHU / TU merger include a commitment of senior management, trust, transparency, giving up of ego and resources, communication between all parties, and mobilization. Analysis of the BHU I TU merger suggests that the process that led to successful integration of the two institutions implicitly followed the methodological steps outlined in the academic literature on mergers. Results highlight the stages of the merger implementation process: identifying the problems; analyzing the constraints and alternatives; choosing the optimal alternative; and implementing the merger. The conclusion of our research demonstrates that the goals set at the beginning of the process were met, as a result of documenting and following up the practical actions of the merger process.
\end{abstract}

Keywords: merger, higher education, mergers and acquisitions, academic mergers

JEL classification: I21, I25, I28

DOI: $10.24818 /$ RMCI.2019.3.241

\section{Introduction}

Founded in 1919 (Gale, 2007), the Baltimore Hebrew University (BHU), a university for Jewish studies, was at a crossroads in 2009 as it faced a decline in external funding, increased competition, and decreased student enrollment. In the Fall of 2009, BHU entered into a vertical merger (i.e. merging a larger university with a smaller one that brings a unique contribution) with Towson University (TU). The present article reviews the background literature on mergers and acquisitions

\footnotetext{
${ }^{1}$ Hana Bor, Towson University-College of Liberal Arts'E-mail: hbor@towson.edu' Telephone: 410-704-5026

${ }^{2}$ Avraham Ketko, "Alexandru Ioan Cuza" University-Tel Aviv-Yafo Municipality, E-mail: ketkoavi@gmail.com
} 
in general, the stages of the merger process, and considers its application to mergers in the academic world. Using the BHU / TU merger as a case study, the paper then analyzes the findings from qualitative research interviews with stakeholders who were involved.

\section{Literature review}

Mergers and acquisitions are management strategies designed to increase the current capacity of a company or companies. Although mergers and acquisitions are often conflated, there are fundamental differences between the two (Coyle, 2000; Thomas, 2009; Zakaria \& Genç, 2017). A merger is a process in which two or more companies make a strategic decision to unite together to form a new company with a new name. The merger is designed to help companies share information, technology, resources, capabilities, finances, markets, customers and more, thereby increasing the overall strength of the company. The merger also reduces risks and strengthens the company against threats and instability. Usually, a merger is established under friendly conditions where both parties (at least at the level of senior management) see the benefits and agree to the merger from the outset. Typically the planning and implementation and execution of the merger is carried out by the new entity or by joint teams who see clearly the purpose of the merged body (Aristos, Georgios, Miltiadis, \& Grigorios, 2018; Bianconi \& Tan, 2019; Ghosh \& Dutta, 2016; Manne, 1965; Vazirani, 2015).

Acquisition, on the other hand, is a process in which one company takes control of another. The acquisition process is usually done by the company that is more powerful and is not always done in friendly conditions. Acquisition is intended to enable the acquiring company to obtain technology or resources that it does not possess, to reduce competition, or to gain new customers, skills, or talent that would otherwise take a long time to develop. Since the acquiring company imposes and enforces its culture, procedures, and norms, the impact on the acquired company there may be unique difficulties in the implementation process (Aristos et al., 2018; Sherman, 2018; Taneja \& Saxena, 2014; Vazirani, 2015).

The literature relates to several types of mergers. Horizontal mergers occur between two companies operating in the same field and/or who compete one another The two companies combine forces and work together to win together a larger market share, reduce competition, expand the circle of customers and improve performance (Brekke, Siciliani, \& Straume, 2017; Correia-da-Silva, Jullien, Lefouili, \& Pinho, 2019; Pavlou, 2015). Vertical mergers occur when two or more companies in the same industry, but in different fields merges together. Such a merger is common among various components of the supply chain, the value chain and/or supplier and customer in the same field. In this framework, the companies decide to integrate production and/or service processes under one roof (Chatterjee, 1991; Li \& Huang, 2013; Kedia, Ravid, \& Pons, 2011). Co-Generic mergers occur between two companies operating in the same field of industry, service and/or close markets, but do not offer the same products. In such a merger, companies can share distribution channels, for example, and gain synergy by doing 
so. These companies have similar technology and production and/or service systems, and therefore it is possible to achieve a relatively easy integration between the various entities (Deshmukh, 2015; Pachulia, 2018; Taneja \& Saxena, 2014). Conglomerate mergers relate to a combination of two companies operating in unrelated industries. The main purpose of conglomerate merger is to achieve growth in activity across various fields in order to expand the business circle (Gabrielsen, 2003; Pachulia, 2018; Taneja \& Saxena, 2014).

Synergy in the context of mergers enable two or more companies to combine forces and thereby generate greater profitability, increase revenue, or reduce expenses. These companies maintain from the outset, that through a common definition of vision, goals and objectives, that the merger offers advantages to both entities above and beyond continuing to operate separately (Devos, Kadapakkam, \& Krishnamurthy, 2008; Fiorentino \& Garzella, 2015). Synergy exists when the value created by the organizational units operating together exceeds the value created by each unit separately. As part of the synergy, it is possible that each company manages its resources separately and only consolidates the results with the other company (modular synergy). Another possibility is that one company completes part of the production and or service process and transfers it to the second company to complete it (subsequent synergy). A third possibility is the mutual synergy which created by continuous and shared work between the companies in a constant process of transferring inputs, outputs and knowledge between them (Zappa, 2008). A different segmentation of synergies can be operational synergy achieved by combining operations and assets between the two organizations that creates better operational efficiency. And synergy created by the transfer of functional skills. This synergy is achieved by transferring knowledge, information or skills and intangible resources between the two companies involved in the merger or acquisition (Morag, 2011).

The "classical" merger process usually includes the following steps (Appelbaum, Gandell, Yortis, Proper, \& Jobin, 2000; DePamphilis, 2016; Galpin, 2014; Miller \& Segall, 2017): 1) Developing a merger strategy - defining the benefits, expectations from the process and the results. Building the rationale, goals, and general perception of the process; 2) Defining a set of criteria for searching and locating potential partners (profit margin, location, customer base, technology, organizational culture, etc.); 3) Searching potential partners according to defined criteria; 4) Planning the merger - Start conversations with one or more potential partners and work with stakeholders to get preliminary information about the option to perform the merge process; 5) Valuation analysis - If the meetings and conversations in the previous stage were successful, request additional information for further examination of the value of the "business deal"; 6) Negotiations - After receiving the information, negotiations can begin on the terms of the merger; 7) Due diligence - a process that begins after the proposal has been accepted and the major conditions have been agreed upon. The purpose of the due diligence is to verify or correct the assessments made in the previous stages in all aspects (finance, assets, liabilities, customers, human resources, etc.); 8) Final agreement and contract; 9) Closing - Summary of the transaction and signing the 
required legal documents; and 10) Beginning of the integration between the two bodies, according to the plan prepared in advance.

The steps described above are sequential, where the execution of each stage is contingent upon the successful completion of previous steps. These steps are principal steps and any merger activity has a specific configuration depending on the people involved and the areas of activity (e.g. whether there are financial aspects or not, etc.). Although these steps pertain to both mergers and acquisitions, merger activity is less "rigid" in terms of assets and due diligence in comparison to acquisitions.

\subsection{Successes and failures}

In addition to describing the process for mergers, the literature provides an understanding of how success and failures can be assessed. Existing literature focuses on methods and means for measuring success and failure and for predicting the chances of success. Some of the measurement methods for success are based on changes in measurable variables such as the performance of the companies after the merger compared to the prior performance level (these indices can be financial, changes in stock value, financial volume of sales, revenue percentage, relative revenue to the average in the industry, etc.). Other metrics and indices are gauged by change in market share, brand strength, and customer satisfaction. Another method of examining the success of mergers is based on the judgment of the managers and stakeholders involved in the process. In this method, interviews and/or questionnaires are performed by the parties involved and a subjective examination of the achievement of the objectives of the process against the initial planning. Of course, in this process one must consider, as is expected, potential subjective biases of the respondents. Another possible way is to rely on external professionals analytical assessment of the success of the mergers (Gomes, Angwin, Weber, \& Yedidia Tarba, 2013; Gong, Zhang, \& Xia, 2019; Schraeder, \& Self, 2003; Straub, 2007; Weber, 2013).

Several factors affect the success of a merger (Nahavandi \& Malekzadeh, 1988; Stensaker, Persson, \& Pinheiro, 2016; Yaghoubi, Yaghoubi, Locke, \& Gibb, 2016). These include: 1) A clear business rationale that is well connected to the company's strategy and has a long-term strategic benefit; 2) The characteristics of the transaction - the type of merger, whether the transaction is friendly or hostile nature. In a friendly process, there is a better chance for cooperation between managers and employees on both sides. Other characteristics such as whether they are local or cross geographical boundaries and necessarily cultural boundaries, the reason for the purchase, the degree of interconnectivity between the companies (the level of similarity between the areas of activity and the businesses of the companies involved), whether there is payment and in what form, the amount of payment, the performance; 3) Characteristics of the companies which are involved in the merger - The size of the company, previous experience in such processes (although each transaction differs from the other and has its own unique characteristics), resources and complementary capabilities between the two 
companies (equipment, knowledge, skills, employees, methods, processes, technological systems, experience, reputation, work routines etc.), level of management and structure of ownership and quantity of owners and the level of internal cooperation; 4) The selection of partners is carried out methodically and carefully while obtaining the maximum amount of information; 5)The early detection of key personnel in the acquired/merged company and their preservation, thus reducing the chances of these people leaving and losing information, knowledge and experience; 6) Integration characteristics - approaches, depth, speed and quality of integration (detailed reference below); 7) Environmental impact social, political, economic, technological, legal and competition in the unique sector; and 8) The results of the acquisition/merger - financial performance, market power, resources and capabilities and areas of activity.

A purchase or merger transaction is usually conceived as part of a strategic move, a business opportunity, a request from another company, publication of a tender or a need resulting from a shortage and/or a crisis. After the strategic decision is made, the preparation stage begins, which is designed to build an appropriate organizational infrastructure. At this stage the organization builds an orderly organizational process for the merger and for defining the desired merger characteristics.

There are two basic methods for locating and searching potential companies: self-search by team members appointed to manage the purchase process and search by an external entity. In the search process there is room to use existing knowledge in the organization regarding various relevant companies. It is also appropriate to use existing organizational interfaces and relationships for that purpose. Typically, the search process results in several companies that meet the basic search criteria defined at the beginning of the process. The next step is to identify a "short list" including a summary table of advantages and disadvantages for each alternative. As part of the gathering of information about potential companies, it is necessary to examine general information, background and history of the company, assets, customers, markets, human capital and any other information relevant to the companies' unique field of activity (Calipha, Tarba, \& Brock, 2010; Drees, 2014; Gupta, 2012; Sherman, 2018;).

After an initial decision, exploratory talks begin and specific proposals are submitted to one or two companies. At the negotiating stage, it is possible to bridge the gaps between the two sides and reach understandings so that each side achieves their most important goal. Other negotiation outcomes may include uncompromising pressure where one side dictates the terms to the other. The negotiation outcome, of course, depends on circumstances, complexity, weaknesses, strengths, etc. (Parola \& Ellis, 2014). Following negotiation, the parties enter the due diligence stage where all merger parameters are examined in a detailed manner. If due diligence is achieved and, the transaction is signed (Brueller, Carmeli, \& Markman, 2018; Howson, 2017; Sherer, Hoffman, Wallace, Ortiz, \& Satnick, 2016). 


\subsection{Integration}

The integration stage focuses on implementing the merger and ultimately assessing the success of negotiation terms. It is critical, then, that this stage is strategically designed to ensure allocation of necessary resources and to give detailed consideration to the impact of the merger. The literature reviews a number of approaches to conceptualizing integration. The first depends on the degree of autonomy of the merged company and the degree of strategic dependence between the two companies (absorption, conservation, symbiosis). A second method centers on leveraging the level of variance between the two companies versus their level of willingness and ability to change. The third approach includes full integration between all organizational functions of the two companies, resulting in full reconstruction or independence (Schönreiter, 2018; Weber, Tarba, \& Bachar, 2011).

An essential issue for integration is the planning and implementation of change across the two organizations with regard to bridging cultural gaps in general and organizational culture in particular. Organizational culture includes a complete set of norms, values, beliefs, assumptions, and history that develops across time into solid patterns unique to each organization. In the process of mergers, two such organizational cultures must be brought together, a matter that requires a professional process of change management, without which the rest of the structure of the merger could collapse. Weber (2013) refers to seven dimensions of organizational culture: an approach to innovation and activity, access to risk, sharing and intra-organizational communication, managers and subordinates, autonomy and decision making, and access to performance. When managing change all of these dimensions must be considered and a suitable plan developed to bridge the gaps (Choi \& Szewczyk, 2018; Kavanagh \& Ashkanasy, 2006).

The risks inherent in the integration process can arise from and be influenced by objections of employees and managers, decreased organizational and personal motivation, uncertainty about the future, lack of understanding of the business and strategic rationale of the entire process, lack of trust between employees and the various levels of management, frequent changes in the organization, and actual activity of management that is contrary to the official declarations and policy. Within the framework of change management addressing such expected obstacles may include: 1) channeling and explaining the course of the merger to employees at different levels using a variety of means; 2) creating a strong internal organizational coalition that supports the process; 3 ) identifying potential obstacles in advance and addressing them proactively; 4) systematically planning for short-term achievements that justify the move; 5) attending to potential time constraints and pressures; and preparing a plan to prevent the departure of key employees (Gupta, 2012; Hoberg \& Phillips, 2018; Sherman, 2018).

\subsection{Mergers in the public sector}

In the public sector mergers have different characteristics from those in the private market. In the private sector cost savings are usually the main reason for the merger. In the public sector, mergers can be performed for reasons that are not 
based solely on calculations of optimization, resource pooling, strong management structures, and financial savings alone. (Torjesen, Geschwind, Berg, Aarrevaara, \& Pinheiro, 2017). For public organizations, the merger is important as a means to develop services in areas such as education, health, and social work (Pinheiro, Geschwind, Aarrevaara, 2013). Mergers in the public sector, then, often center on their social benefits.

\subsection{Mergers in the academic world}

Universities and institutions of higher education in countries across the globe face a changing environment, globalization, impulse to quality, new technologies, new teaching requirements, increased thinking of research and innovation, and above all a different and challenging economic environment (Curaj, Georghiou, Harper, \& Egron-Polak, 2015; Kyvik \& Stensaker, 2013; Pruvot, 2015). Traditional funding for higher education is changing and public funding is not always available. Harman and Harman (2003) argue that higher education is faced with the fragmentation of institutions of academic education, as well as regulatory requirements of governments (supervision, control, and the desire that these institutions serve the local and national economy more directly, while meeting social goals). In addition, higher education faces the growing demands for improving student access while offering a wider range of courses to reach a broader and more diverse population of students.

Ljungberg, Johansson and McKelvey (2009) write that European universities have faced significant changes in recent years - an increase in the number of students, a decline in research funding, and a new type of commitment to society. In Sweden, the authors note, the university system is undergoing a change similar to the English system in which universities must compete for resources. Unlike the United States where this trend has existed for many years, European countries have only in the last few decades evolved to a model of such competition. In addition, policymakers' attitudes (especially government officials ) are shifting beliefs that the systems of higher education are inefficient, below performance levels, and need to be reorganized (liu, Patton, \& Kenney, 2018).

The basic idea of the university institution and the rationale of higher education still exists. However, the circumstances that existed during the establishment of academic institutions and their development over the years have changed and no longer meet the expectations of the stakeholders (Georghiou \& Harper, 2015). The literature documents a wave of mergers and alliances in the area of higher education at the end of the twentieth century continuing through recent years as a response and reaction to these trends (Curaj at al., 2015; Harman $\&$ Meek, 2002).

The issue of cooperation, collaboration, and partnerships between academic institutions and higher education, is not foreign to these organizations. Academic institutions are accustomed to joint research, resource sharing, accreditation arrangements between different institutions, establishment of joint institutes, exchange of lecturers, and other forms of academic cooperation. These 
arrangements may include informal collaborations such as joint use of expensive or specific and rare equipment. Such participation is usually organized by individual faculty members or departments within the academic institution. More formal collaborations include research based on co-financing, co-ownership of assets, including non-tangible assets (such as research results and patents). Some of these partnerships are already based on written agreements and/or commercial/legal agreements. Others are defined as a combination of two or more separate organizations that all management and control converge under one governing entity and one C.E.O (Harman \& Harman, 2003).

In a report submitted to the European University Association, Pruvot (2015) examines various types of integration processes between academic institutions in which the partner institutions decide to maintain certain characteristics of each of them within the framework of the institution to which they merged until full mergers. These mergers can be "horizontal" mergers of institutions of the same size and "vertical" mergers in which an academic institution merges with a small institution specializing in specific knowledge (the report notes 92 mergers in 2000-2015 across Europe). The report points to a wide range of mergers stemming from the need to improve academic quality, promote academic strategic objectives, preference of public funding mechanisms to finance larger institutions, economies of scale, more professional services, cost reduction, system consolidation, prevent duplication, and institutional strengthening. Mao et al., (2009), show that this phenomenon is global and exists in all continents and countries. In the years 1992-2000, there were more than 350 such mergers in China. Georghiou and Harper (2015) present national aspiration as another motive for university consolidation.

Ursin, Aittola, Henderson and Välimaa (2010) emphasize that although one of the declared goals of most university mergers is to improve the quality of education, mergers are also the result of social pressures to change the structure of higher education in light of a reduction in public funding and an increasing number of academic staff. For example, the Minister of Education and Culture of Finland forced the universities to merge to deal with this phenomenon. Its purpose was to reorganize the higher education system in Finland, to enable greater competitiveness of institutions of higher education, and to improve the quality of research. Liu, Patton and Kenney (2018) also point to government guidance as an impetus for academic mergers. Many academic mergers can be tied to policymakers' beliefs that the educational system is inefficient, under-performing, and needs to be reorganized. These mergers are part of a broad reform to improve academic and administrative quality.

Norgård and Skodvin, (2002) describe the usefulness of mergers from a facilities standpoint. A network of academic institutions is more expensive to operate than a single integrated physical institution. It is more difficult to achieve cooperation and integration of a cross-curricular program without a faculty with a single campus. In such a case it is difficult to distinguish which problems were created due to geographical distance and which problems arise due to cultural 
differences between members of different backgrounds and different institutions with different professional identities.

Like other merger processes, planning is perhaps the most important stage in the entire process of academic mergers. A successful merger requires the development of a new structure, new ways of working together with the adoption of new ways of thinking within the evolving academic community. The University's management plays a critical role in bringing the merger to work and creating a new organizational culture. Proper organizational leadership should create a vision for a merger that maintains the strengths of the merging academic institutions and yet responds to the external constraints that were among the factors for initiating the process to begin with (Ursin et al., 2010). The merger process must take into account the heterogeneity of organizational cultures and subcultures in order not to pose additional risks. In addition, the efficiency of the new merged institution will not replace its academic and scientific development. For academic staff, the merger can have both positive and negative implications. The merger can improve professional identity, give prospects for a better academic career, a new allocation of resources; however, tension can arise between the teaching staff precisely because of the same circumstances (Locke, 2007; Ursin et al., 2010).

\subsection{Merger between BHU \& TU: A case study}

The Baltimore Hebrew University was founded in 1919 and began as a teacher training institution for Jewish schools (Gale, 2007). Over the years, the school developed into a college offering advanced degrees in Jewish education and Jewish studies (Mael, 2014). In 1987, the institution received academic status and awarded doctoral students together with dual degrees of cooperation with other academic institutions, including the Towson University in Baltimore. Founded in 1860, Towson University also began as a teacher's college. In 1980 it became part of the higher education system of the State of Maryland. The university includes seven colleges in various fields, including liberal arts, health, the performing arts, technology and business. In 2009, the University included 21,000 students (Esslinger, Knox, \& Nasr, 2016).

Following trends in academic both within and outside of the United States (Curaj et al., 2015; Kyvik \& Stensaker, 2013; Pruvot, 2015), BHU was at a crossroads in. A number of significant factors had led BHU to consider that the best solution was to merge with another academic institution. Following a methodological process led by responsible and professional leadership (Bor \& Shargel, 2019), BHU merged with Towson University. We first describe our qualitative approach to our case study, followed by the presentation of findings.

\section{Research design}

The present research method is based on a constructive approach (Bryman and Bell, 2015). Because one of the authors was a participant-observer to the process we used both grounded theory and case study design techniques (Charmaz,

Review of International Comparative Management

Volume 20, Issue 3, July 2019 
2014; Creswell, 2014). The purpose of this study was to learn and understand from first-hand stakeholders who were involved in the merger process and participated in the decision-making. From their perspective we developed a narrative regarding the way things happened, the motives and reasons for the merger, the methods taken, the interpersonal relationships that took shape during the process, the trust relations built, and the shifts in organizational culture that supported the merger.

The participants in the study were fifteen senior managers and members of management who were involved in all stages of the merger and experienced the process personally. Semi-structured interviews were conducted with the questions such as: background questions, how the process works, the relationships between the teams' members (formal and informal), the extent of trust between them, the flow of information and the senior management commitment to the process. Data were collected through those individual semi-structured interviews and first analyzed using open coding. The researchers then used axial coding to reconstruct the data in new ways by making connections between the categories. The categories emerging from open and axial coding were the basis for the findings as revealed through the analysis of the data collected.

\section{Findings}

Based on the interviews conducted with the stakeholders involved in the merger process the following themes emerged from the data. Themes were classified into categories and arranged in a linear time sequence when relevant. These are detailed below.

- Over the years, BHU relied on external funding for most of its budget totaling over \$1 million.

- The funding stream was steadily reduced as a result of additional needs and channeling funding resources to other issues in accordance with changing priorities (e.g. community support and other community institutions).

- As a result of competition from similar institutions in the region, there was a decrease in the number of students enrolled.

- Policy makers did not see fit to continue holding the institution in light of the required investment.

- Strong competition developed from large universities that offered a similar "product" with a higher added value that included wider and varied academic possibilities.

- As a result of the reduction of resources, physical structures and buildings were not renewed, upgraded, or renovated over the years. Campus facilities, therefore, were less attractive to new students.

- The university did not have enough resources to allow for proper and professional treatment for the preservation of the rare books and manuscript collections in their possession.

$250 \quad$ Volume 20, Issue 3, July 2019

Review of International Comparative Management 
- BHU had a strong reputation for Jewish studies based upon the curriculum and the merit of a long-standing legacy of high-quality graduates who were integrated into senior positions in the community leadership.

- There was a discussion and dialogue between stakeholders and policy makers about how to allocate resources among all community systems along with the right way to develop higher education.

- There was general agreement that the environment had changed and that a new way of financing and changing the subsidy system had to be found, based on governmental and international sources.

- The final conclusion and decision was that the most appropriate solution to the problems described so far was a merger with another university.

- As a preliminary stage, the strengths and benefits of BHU were outlined: a mature series of study programs, three advanced programs for advanced students, diverse programs, skilled staff, philanthropic support, a library with valuable books and manuscripts, a dedicated curriculum of Judaism from a historical and scientific point of view, a continuation of funding for three years of faculty for community studies.

- Mapping the relevant academic institutions for the potential merger. Initial exploratory meetings were held with a large number of these institutions to examine the idea and its feasibility.

- The merits of a merger with Towson University were determined to be based upon the following: geographical closeness, preservation of uniqueness, recognition of TU's studies and continuity, TU's desire to incorporate a Department of Religious Studies into the Liberal Arts College, to develop PhD studies (for which it was not licensed at the time), the ability to absorb faculty members, the possibility of including the new teaching staff in a recently completed building and the professional and technical ability to absorb the library's special academic materials.

- Personal bonds, trust between leaders and the high commitment of the two presidents, built the interpersonal infrastructure. This desire and commitment were presented to the other stakeholders at all levels of decision-making and work, the nature of the merger, its importance and the enlistment for its success.

- Construction of a work team to plan the merger process in the academic and administrative aspects, integrating the teaching staff, building an integrated curriculum and determining how to continue the studies of the students who are in the middle of the various programs.

- Giving up the ego and other resources of the stakeholders were key to the promotion of the merger (forego the role of the president of BHU as part of the merger and the teaching staff agreed to give up their tenure as part of the transition). The ability of the senior management to "rise above" the process and see the vision and objectives.

- The absorption of BHU staff within TU University was done professionally, embracing, identifying difficulties and providing a solution for each 
of them, while discovering empathy and change management as part of the absorption process.

- The university registrar, in coordination with the other stakeholders, was firmly involved in finding a solution to all the bureaucratic issues that arose before and during the absorption of the students in a very professional manner. $\mathrm{He}$ recognized the need not to harm the students who were in the middle of the various curricula and allowed a smooth transition between the two institutions.

- The curriculum and the various courses (about 50) were integrated into the University's study programs in the fields of Jewish history, philosophy, education and Hebrew language.

- Students of the former BHU have access to many resources they did not have previously (writing centers, technological training, improved physical conditions, advanced library resources, etc.).

- BHU teaching staff would enjoy better personal benefits (health insurance, access to a government pension fund), as well as academic and other research services, as a consequence of the merger.

- Some of the teaching staff in the two institutions and other stakeholders in the community expressed opposition to the move. This resistance stemmed either from the loss of uniqueness as a result of the merger with a larger institution, the loss of access by the community to BHU facilities (such as a library), and the concern of a number of TU faculty members against new educational content and misunderstanding of basic concepts in Jewish studies.

- The establishment of an institute for Jewish studies (BHI - Baltimore Hebrew Institute), which will continue to receive scholarships, will support the collection of books and enable adult studies in a non-degree course.

\section{Discussion and Conclusions}

The strength of the findings of our case study rest in understanding the themes that emerged from the interviews with stakeholders in the BHU / TU merger. Importantly, this analysis allowed assessment of the merger's success as gleaned from the perspective of individuals who were partners in various aspects of the merger and whose perspectives were informed by their role at the time. In addition, the findings describe the order of events from the stage of the initiating circumstances and factors leading to the merger, through detailing the sequence of the resulting process.

A comparison of the findings, as shown in the interviews, to the literature on merger processes in general and in the academic world in particular, shows a high correlation between the two. Both universities have similar backgrounds in that they both began as teacher training schools and over the years developed into institutions with academic recognition. In addition, the two institutions had a past history of cooperation in joint studies. The literature mentions this issue as a factor for the success of mergers between organizations with a history of sharing and 
cumulative experience (Aristos et al., 2018; Bianconi \& Tan, 2019; Ghosh \& Dutta, 2016).

The environmental changes and external constraints faced by BHU decision makers (decrease in funding, change in the priorities of policy makers, competition from other academic institutions, decrease in student registration, etc.) are almost an exact copy of the constraints examined in the literature and that face hundreds of academic institutions worldwide. The solution of the merger chosen by the stakeholders is also consistent with the literature (Curaj et al., 2015; Kyvik \& Stensaker, 2013; Pruvot, 2015).

Once identified by these constraints, the university senior management adopted the decision and acted in a systematic and methodological manner in accordance with the stages described in the general literature and literature on mergers in the academic world step by step, which eventually led to the desired merger result for both sides. BHU's management mapped its strengths according to the needs of the merger, examined the various alternatives and chose the best option. Towson University has also been a natural partner due to its geographical location, due to past experience, and the benefits of BHU have met the needs and intentions of its academic development. Each side found the other side complementary its shortcomings, and thus actually reached a synergistic merger between them in the academic and administrative aspects. (Devos el al., 2008; Fiorentino \& Garzella, 2015)..

The commitment of the presidents of the two universities, the trust and transparency between them, permeated the various levels of management and work teams and all of them were recruited for the success of the process. Stakeholders at different stages were able to put the interests of the common good and the process ahead of their own interests and to harness to its success (Gomes et al., 2013; Gong et al., 2019; Parola \& Ellis, 2014).

During the merger, a great deal of emphasis was placed on the process of absorbing students into various departments and to reduce the harm to their educational progress as a result of their transition to TU. A similar process was carried out for faculty and staff (administrative and academic) impacted by the transition. Care was taken to address their specific concerns as they were both physically and professionally repositioned in a new place.

This particular merger between BHU and TU corresponds to the "vertical" merger model, which is expressed in the literature as a merger between a large university and an institution of a smaller scale, but one that has a special uniqueness and appeal (Chatterjee, 1991; Kedia et al., 2011; Li \& Huang, 2013). $\mathrm{BHU}$ contributes to the unification in bringing its unique contribution of religious studies and the licensing of PhD degrees into the institution of TU.

In view of all of the above, and in view of the analysis of the responses in interviews and the literature, one of the factors contributing to the success of the merger between BHU and TU is based on systematic, orderly, and consistent implementation of the methodological stages of the merger and acquisitions process. It can be seen that the leaders of the process on both sides, acted "by the book" step by step, did not allow chance to interfere with the process, and therefore 
- could eventually reach a desired outcome in accordance with the vision and goals set in the beginning.

It is possible to see that the strictness and implementation of all the various components were part and infrastructure of the entire process: The identification of environmental changes and external constraints, analysis of the various options, mapping of strengths and weaknesses, deep commitment of senior management, trust, mutual appreciation and transparency among the various stakeholders, a mutual response to the needs of each side, giving up ego and personal interests to the success of the merger, placing the best interests of the institution and the process at the top of the priorities, change management in a professional way in those cases of resistance and other components.

This methodical practice, which follows all stages led to a successful merger to the satisfaction of all parties at the end of the process.

\section{References}

1. Appelbaum, S. H., et al., 2000. Anatomy of a merger: behavior of organizational factors and processes throughout the pre-during-post-stages (part 1). Management decision, 38(9), 649-662.

2. Aristos, D., Georgios, S., Miltiadis, C., \& Grigorios, K., 2018. The Impact of Mergers and Acquisitions on Corporate Culture and Employees: The Case of Aegean \& Olympic Air. Academy of Strategic Management Journal, 17(1).

3. Bianconi, M., \& Tan, C. M., 2019. Evaluating the instantaneous and mediumrun impact of mergers and acquisitions on firm values. International Review of Economics \& Finance, 59, 71-87.

4. Bor, H. \& Shargel, R., 2019. The merger of Baltimore Hebrew University and Towson University: Three leadership models converge. International Journal of Educational Management.

5. Brekke, K. R., Siciliani, L., \& Straume, O. R., 2017. Horizontal mergers and product quality. Canadian Journal of Economics/Revue canadienne d'économique, 50(4), 1063-1103.

6. Brueller, N. N., Carmeli, A., \& Markman, G. D., 2018. Linking merger and acquisition strategies to postmerger integration: a configurational perspective of human resource management. Journal of Management, 44(5), 1793-1818.

7. Bryman, A., \& Bell, E., 2015. Business research methods, (4th ed.). USA: Oxford University Press.

8. Calipha, R., Tarba, S., \& Brock, D., 2010. Mergers and acquisitions: a review of phases, motives, and success factors. In S. Finkelstein , C. L. Cooper (Eds.), Advances in Mergers and Acquisitions Vol 9. (pp. 1-24). Emerald Group Publishing Limited.

9. Charmaz, K., 2014. Constructing grounded theory: A Practical Guide Through Qualitative Analysis, (2th ed.). London: Sage Publications.

$254 \quad$ Volume 20, Issue 3, July $2019 \quad$ Review of International Comparative Management 
10. Chatterjee, S., 1991. Gains in vertical acquisitions and market power: Theory and evidence. Academy of Management Journal, 34(2), 436-448.

11. Choi, S. H., \& Szewczyk, S. H., 2018. Corporate governance structure and strategic change: evidence from major acquisitions. Managerial Finance, 44(2), 222-240.

12. Correia-da-Silva, J., Jullien, B., Lefouili, Y., \& Pinho, J., 2019. Horizontal mergers between multisided platforms: Insights from Cournot competition. Journal of Economics \& Management Strategy, 28(1), 109-124.

13. Coyle, B., 2000. Mergers and Acquisitions (Vol. Library ed). Chicago: AMACOM. Retrieved from https://search-ebscohost-com.elib.openu.ac.il/ login.aspx?direct=true $\& d b=$ nlebk $\& A N=52734 \&$ site $=$ eds-live

14. Creswell, J. W., 2014. Research Design: Qualitative, Quantitative, and Mixed Methods Approaches, (4th ed.). London: Sage Publications.

15. Curaj, A., Georghiou, L., Harper, J. C., \& Egron-Polak, E., 2015. Mergers and alliances in higher education: International practice and emerging opportunities. N.Y.: Springer Open.

16. DePamphilis, D., 2016. Mergers, acquisitions, and other restructuring activities: An integrated approach to process, tools, cases, and solutions (8th ed.). Academic Press.

17. Deshmukh, R. V., 2015. Impact of Mergers and Acquisitions on Changing Roles of HR. KHOJ: Journal of Indian Management Research and Practices, 287-297.

18. Devos, E., Kadapakkam, P. R., \& Krishnamurthy, S., 2008. How do mergers create value? A comparison of taxes, market power, and efficiency improvements as explanations for synergies. The Review of Financial Studies, 22(3), 1179-1211.

19. Drees, J. M., 2014. (Dis) Aggregating alliance, joint venture, and merger and acquisition performance: A meta-analysis. In S. Finkelstein , C. L. Cooper (Eds.), Advances in Mergers and Acquisitions Vol 13. (pp. 1-24). Emerald Group Publishing Limited.

20. Esslinger, D. R., Knox, F., \& Nasr, N., 2016. Towson University: The First 150 Years. Towson University.

21. Fiorentino, R., \& Garzella, S., 2015. Synergy management pitfalls in mergers and acquisitions. Management Decision, 53(7), 1469-1503.

22. Gabrielsen, T. S., 2003. Conglomerate mergers: Vertical mergers in disguise?. International Journal of the Economics of Business, 10(1), 1-16.

23. Galpin, T. J., 2014. The complete guide to mergers and acquisitions: Process tools to support M\&A integration at every level. John Wiley \& Sons.

24. Gale, T., 2007. Baltimore Hebrew University. Encyclopedia Judaica. Retrieved May 11, 2019 from Encyclopedia.com: https://www.encyclopedia. com/religion/encyclopedias-almanacs-transcripts-and-maps/baltimore-hebrewuniversity 
25. Georghiou, L., \& Harper, J. C., 2015. Mergers and alliances in context. In A. Curaj, L. Georghiou, J. C. Harper, \& E. Egron-Polak, (Eds.), Mergers and Alliances in Higher Education International Practice and Emerging Opportunities, (pp. 1-14). N.Y.: Springer Open.

26. Ghosh, S., \& Dutta, S., 2016. Mergers and acquisitions: A comparative review of literature. Industrija, 44(1), 187-208.

27. Goksoy, A., 2019. Cultural Integration in Mergers and Acquisitions. In A. c. Moreira \& P. Silva (Eds.), Handbook of Research on Corporate Restructuring and Globalization (pp. 101-124). IGI Global.

28. Gomes, E., Angwin, D. N., Weber, Y., \& Yedidia Tarba, S., 2013. Critical success factors through the mergers and acquisitions process: revealing preand post-M\&A connections for improved performance. Thunderbird international business review, 55(1), 13-35.

29. Gong, Y., Zhang, Y., \& Xia, J., 2019. Do firms learn more from small or big successes and failures? A test of the outcome-based feedback learning perspective. Journal of Management, 45(3), 1034-1056.

30. Gupta, P. K., 2012. MERGERS AND ACQUISITIONS (M\&A): THE STRATEGIC CONCEPTS FOR THE NUPTIALS OF CORPORATE SECTOR. Innovative Journal of Business and Management, 1(04).

31. Harman, G., \& Harman, K., 2003. Institutional mergers in higher education: Lessons from international experience. Tertiary Education and management, 9(1), 29-44.

32. Harman, K., \& Meek, V. L., 2002. Introduction to special issue: "Merger revisited: international perspectives on mergers in higher education". Higher Education, 44(1), 1-4.

33. Hoberg, G., \& Phillips, G. M., 2018. Product integration and merger success. Tuck School of Business Working Paper, (2933283), 17-21.

34. Howson, P., 2017. Due diligence: The critical stage in mergers and acquisitions. Routledge.

35. Kavanagh, M. H., \& Ashkanasy, N. M., 2006. The impact of leadership and change management strategy on organizational culture and individual acceptance of change during a merger. British journal of management, 17(S1), S81-S103.

36. Kedia, S., Ravid, S. A., \& Pons, V., 2011. When do vertical mergers create value?. Financial Management, 40(4), 845-877.

37. Kyvik, S., \& Stensaker, B., 2013. Factors affecting the decision to merge: The case of strategic mergers in Norwegian higher education. Tertiary Education and Management, 19(4), 323-337.

38. Li, J., \& Huang, X., 2013. When to initiate an international vertical merger? The impact of negative demand shock. The World Economy, 36(7), 843-860.

$256 \quad$ Volume 20, Issue 3, July $2019 \quad$ Review of International Comparative Management 
39. Liu, Q., Patton, D., \& Kenney, M., 2018. Do university mergers create academic synergy? Evidence from China and the Nordic Countries. Research Policy, 47(1), 98-107.

40. Ljungberg, D., Johansson, M., \& McKelvey, M., 2009. Polarization of the Swedish university sector: Structural characteristics and positioning. Learning to compete in European universities: From social institution to knowledge business, 128-59.

41. Locke, W., 2007. Higher education mergers: Integrating organizational cultures and developing appropriate management styles. Higher Education Quarterly, 61(1), 83-102.

42. Mael, E., 2014. When one plus one remains one. Library Resources \& Technical Services, 58(4), 265-278.

43. Manne, H. G., 1965. Mergers and the market for corporate control. Journal of Political economy, 73(2), 110-120.

44. Mao, Y. Q., Du, Y., \& Liu, J. J., 2009. The effects of university mergers in China since 1990s: From the perspective of knowledge production. International Journal of Educational Management, 23(1), 19-33.

45. Miller Jr, E. L., \& Segall, L. N., 2017. Mergers and Acquisitions, + Website: A Step-by-Step Legal and Practical Guide. John Wiley \& Sons.

46. Morag, O., 2011. Mergers and Acquisitions. Design, planning and implementation strategy. Tel-Aviv: Globes - Israel business Arena. (In Hebrew).

47. Nahavandi, A., \& Malekzadeh, A. R., 1988. Acculturation in mergers and acquisitions. Academy of management review, 13(1), 79-90.

48. Norgård, J. D., \& Skodvin, O. J., 2002. The importance of geography and culture in mergers: A Norwegian institutional case study. Higher Education, 44(1), 73-90.

49. Pachulia, O., 2018. Impact of Mergers and Acquisitions on Corporate Performance: A Case study of Silknet Company. Ecoforum Journal, 7(3).

50. Parola, H., \& Ellis, K. M., 2014. M\&A negotiation stage: A review and future research directions. In Advances In S. Finkelstein , C. L. Cooper (Eds.), Advances in Mergers and Acquisitions Vol 12. (pp. 33-57). Emerald Group Publishing Limited.

51. Pavlou, A., 2015. Learning by doing and horizontal mergers. Journal of Economics, 116(1), 25-38.

52. Pinheiro, R., Geschwind, L., Aarrevaara, T., 2013. Mergers in higher education and beyond: stocktaking and assessment. https://www.divaportal.org/smash/get/diva2:815407/FULLTEXT01.pdf

53. Pruvot, E. B., Estermann, T., \& Mason, P., 2015. DEFINE thematic report: University mergers in Europe. Brussels: European University Association.

54. Schönreiter, I. M., 2018. Methodologies for process harmonization in the post-merger integration phase: A literature review. Business Process Management Journal, 24(2), 330-356. 
55. Schraeder, M., \& Self, D. R., 2003. Enhancing the success of mergers and acquisitions: an organizational culture perspective. Management Decision, 41(5), 511-522.

56. Sherer, J. A., Hoffman, T. M., Wallace, K. M., Ortiz, E. E., \& Satnick, T. J., 2016. Merger and acquisition due diligence part II-the devil in the details. Richmond Journal of Law \& Technology, 22(2), 4.

57. Sherman, A., 2018. Mergers and Acquisitions from A to $Z$ (4th ed.). N.Y.: Amacom.

58. Stensaker, B., Persson, M., \& Pinheiro, R., 2016. When mergers fail: a case study on the critical role of external stakeholders in merger initiatives. European Journal of Higher Education, 6(1), 56-70.

59. Straub, T., 2007. Reasons for frequent failure in Mergers and Acquisitions: A comprehensive analysis. Springer Science \& Business Media.

60. Taneja, M., \& Saxena, N., 2014. Mergers and acquisitions with a reference to ethical, social and human resource. IOSR Journal of Business and Management, 16(3), 69-72.

61. Thomas, M., 2009. Mergers and Acquisitions : Confronting the Organization and People Issues (Vol. 2nd ed). London: Thorogood Publishing Ltd. Retrieved from https://search-ebscohost-com.elib.openu.ac.il/login.aspx? direct $=$ true $\& \mathrm{db}=$ nlebk $\& A N=322135 \&$ site $=$ eds-live

62. Torjesen, D. O., Geschwind, L., Berg, L. N., Aarrevaara, T., \& Pinheiro, R., 2017. Strategic mergers in the public sector: comparing universities and hospitals. In S. Y. Tarba, C. L. Cooper, R. M. Sarala, \& M. F. Ahammad, (Eds.), Mergers and Acquisitions in Practice (pp. 58-82). N.Y.: Routledge.

63. Ursin, J., Aittola, H., Henderson, C., \& Välimaa, J., 2010. Is education getting lost in university mergers?. Tertiary education and management, 16(4), 327-340.

64. Vazirani, N., 2015. A Literature Review on Mergers and Acquisitions Waves and Theories. SIES Journal of Management, 11(1).

65. Weber, Y. (2013). A comprehensive guide to mergers \& acquisitions: Managing the critical success factors across every stage of the M\&A process. FT Press.

66. Weber, Y., Tarba, S. Y., \& Bachar, Z. R. (2011). Mergers and acquisitions performance paradox: the mediating role of integration approach. European Journal of International Management, 5(4), 373-393.

67. Yaghoubi, R., Yaghoubi, M., Locke, S., \& Gibb, J. (2016). Mergers and acquisitions: a review. Part 1. Studies in Economics and Finance, 33(1), 147-188.

68. Zakaria, R., \& Genç, Ö. F. (2017). Alliances to Acquisitions: A Road Map to Advance the Field of Strategic Management. In C. L. Cooper, \& S. Finkelstein (Eds.), Advances in Mergers and Acquisitions vol 16 (pp. 1-20). UK: Emerald Publishing Limited.

69. Zappa, M. (2008). The Fundamentals of Strategic Logic and Integration for Merger and Acquisition Projects. Management, Economics and Technology, 42-61.

$258 \quad$ Volume 20, Issue 3, July $2019 \quad$ Review of International Comparative Management 